\title{
Ações ambientais no processo de gestão de empreendimentos rodoviários na Amazônia Mato-Grossense
}

\author{
Environmental actions in the process management of highway undertakings in the Amazon Mato- \\ Grossense
}

\begin{abstract}
Acciones ambientales en el proceso de gestación de desarrollo de carreteras em el Amazonas Mato-Grossense
\end{abstract}

Onelia Carmem Rossetto - Universidade Federal de Mato Grosso | Pesquisadora Associada ao Programa de Pós-Graduação em Geografia - PPGEO | Cuiabá | MT | Brasil. E-mail: carmemrossetto@ gmail.com |

(1) ORCID

Giseli Dalla Nora - Universidade Federal de Mato Grosso | Departamento de Geografia | Cuiabá | MT | Brasil. E-mail: giseli.nora@gmail.com | (1) orci

Resumo: A Educação Ambiental representa um subprograma de relevância durante o processo de licenciamento ambiental de empreendimentos rodoviários e assume conotações peculiares em biomas vulneráveis como a Amazônia Mato-Grossense. Para tanto, alguns atores, como gestores públicos municipais e sociedade civil, representam sujeitos da pesquisa que teve como objetivos analisar a forma como concebem os problemas socioambientais, como organizam a estrutura de governança em relação às questões ambientais e identificar como articulam suas ações aos mecanismos de controle social e ao desenvolvimento de ações ambientais no âmbito formal e não-formal da educação. Os pressupostos metodológicos consistiram na coleta de dados secundários, pesquisa documental, diagnóstico socioambiental participativo. Os resultados levantados com as oficinas realizadas apontam que a realidade socioambiental é a base de sustentação das ações e o controle social é limitado pela ideia de que os conselhos são instâncias deliberativas e não decisórias.

Palavras-chave: Educação ambiental. Amazônia Mato-Grossense. Empreendimentos rodoviários. Gestão ambiental.

Abstract: Environmental Education represents a relevant sub-program during the environmental licensing process for road undertakings and takes on peculiar connotations in vulnerable biomes such as the Amazon Mato Grosso. To this end, some actors, such as municipal public managers and civil society, represent research subjects whose objectives were to analyze the way they conceive socio-environmental problems, how they organize the governance structure in relation to environmental issues and to identify how they articulate their actions to the mechanisms social control and the development of environmental actions in the formal and non-formal scope of education. The methodological assumptions consisted of collecting secondary data, documentary research, participatory socio-environmental diagnosis. The results obtained with the workshops carried out show that the socio-environmental reality is the basis for sustaining the actions and social control is limited by the idea that the councils are deliberative and not decision-making bodies.

Keywords: Environmental education. Amazonia Mato-Grossense. Roadway undertakings. Environmental management.

- Recebido em 01 de junho de 2019 • Aprovado em 28 de novembro de 2019 • e-ISSN: 2177-5796

DOI: http://dx.doi.org/10.22483/2177-5796.2020v22n2p569-588

Copyright @ 2019. Conteúdo de acesso aberto, distribuído sob os termos da Licença Internaonal da CreativeCommons - CC BY-NC-SA Atribuição Não Comercial (https://br.creativecommons.org/licencas/) - Permite distribuição e reprodução, desde que atribuam os devido créditos à publicação, ao autor(es) e que licenciem as novas criações sob termos idênticos. 
ROSSETTO, Onelia Carmem; NORA, Giseli Dalla. Ações ambientais no processo de gestão de empreendimentos rodoviários na Amazônia Mato-Grossense.

Resumen: La Educación Ambiental representa un subprograma relevante durante el proceso de licenciamiento ambiental para emprendimientos viales y adquiere connotaciones peculiares en biomas vulnerables como el Amazonas Mato Grosso. Con este fin, algunos actores, como los administradores públicos municipales y la sociedad civil, representan temas de investigación que tienen como objetivo analizar la forma en que conciben los problemas socioambientales, cómo organizan la estructura de gobernanza en relación con los problemas ambientales e identifican cómo articulan sus acciones a los mecanismos. control social y desarrollo de acciones ambientales en educación formal y no formal. Los supuestos metodológicos consistieron en la recolección de datos secundarios, investigación documental, diagnóstico socioambiental participativo. Los resultados obtenidos con los talleres realizados muestran que la realidad socioambiental es la base para sostener las acciones y el control social está limitado por la idea de que los consejos son deliberativos y no órganos de toma de decisiones.

Palabras clave: Educación ambiental. Amazonas Mato-grossense. Desarrollo de carreteras. Gestión ambiental. 


\section{Introdução}

As transformações socioambientais na Amazônia brasileira estão associadas à hegemonia de um modelo exploratório, em que a racionalidade capitalista prioriza a expansão do agronegócio e o aumento dos superávits comerciais, causando danos socioambientais, por vezes, irreversíveis. Lemos e Silva (2011) afirmam que, até 2009, o Mato Grosso foi o estado da Amazônia Legal com maior perda de Bioma Amazônia, 59,12\%; e em conjunto com o Pará, com taxas de 32,73 e 35,45\%, respectivamente, contribuem com quase $70 \%$ do Bioma da Amazônia que já foi retirado.

O município de Nova Ubiratã, localizado na mesorregião Norte Mato-Grossense, no Bioma Amazônia, surgiu em 1952 como uma gleba denominada Rio Ferro, através de dois projetos de colonização privada, distantes aproximadamente $15 \mathrm{~km}$ do atual perímetro urbano de Nova Ubiratã. Tal gleba foi, posteriormente, colonizada pela Comércio de Imóveis Pinheiros Ltda. (COMPIL) e elevada à categoria de município pela Lei Estadual nº 6691, de 30/11/1995 (MATO GROSSO, 1995). As colonizadoras particulares com apoio do governo federal incentivavam a extração madeireira e a agropecuária, atividades que são os principais componentes da base econômica do município até a atualidade.

A expansão e modernização da agropecuária em geral originam impactos de ordem socioambiental nas diferentes áreas ocupadas pelo cultivo de soja e pela bovinocultura, principalmente através das técnicas de manejo inadequadas, a exemplo das queimadas. Dados do Programa de Monitoramento de Queimadas do Instituto Nacional de Pesquisas Espaciais (INPE) mostram que houve redução de mais de 25 mil km² da Floresta Amazônica em 2004, para cerca de $6.200 \mathrm{mil} \mathrm{km}^{2}$ em 2015. Os focos de incêndios somaram 87.000 em 2015. O manejo inadequado resulta em impactos socioambientais negativos, expressos pela perda de biodiversidade e de funções ecossistêmicas, tais como armazenamento de carbono, regulação do clima e equilíbrio hidrológico.

À medida que avança a exploração econômica dos elementos naturais, se faz necessário acréscimos nos modais de transporte visando à mobilidade, tanto da população quanto da produção, entre eles a rodovia BR-242, que perpassa os estados da Bahia, Tocantins, seguindo até o estado do Mato Grosso com extensão de 2.311,7 km (Figura 1). 
Figura 1 - Traçado completo da BR-242

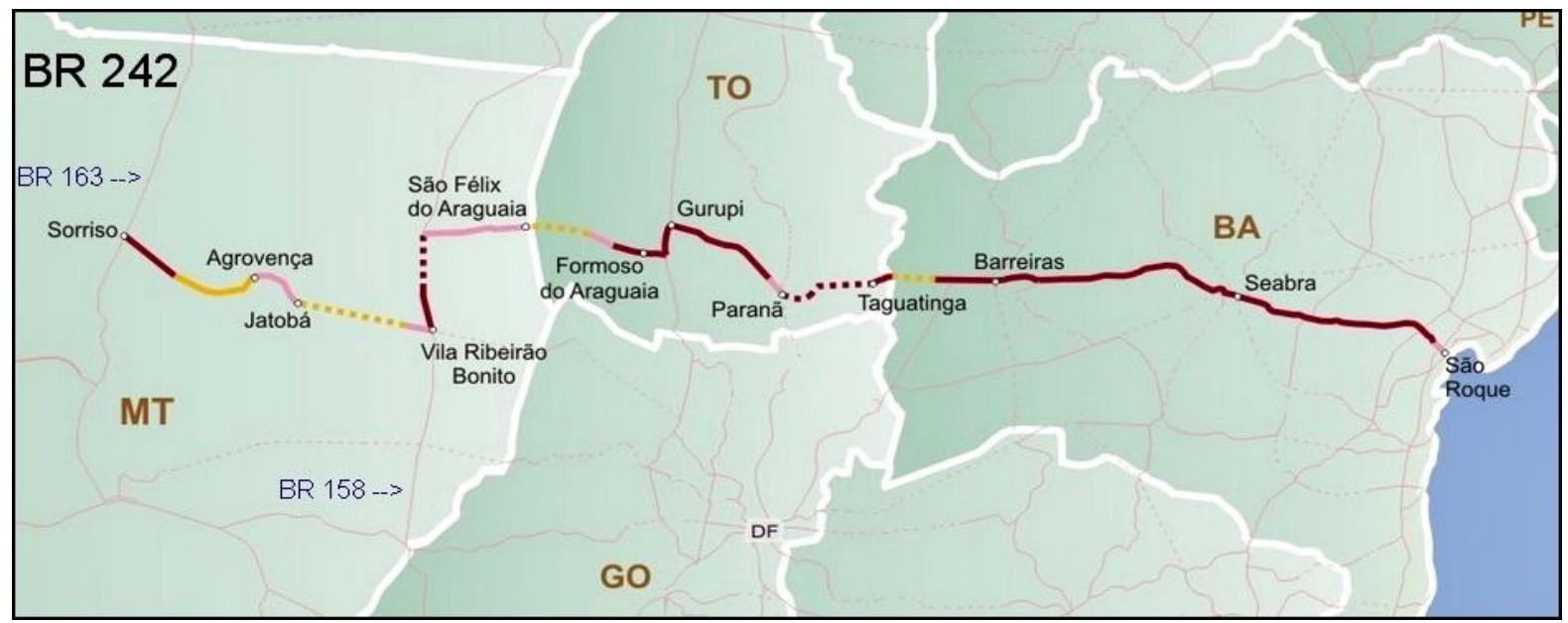

Fonte: MELBY, K. Mapa BR-242. Disponível em: https://www.sonoticias.com.br/uncategorized/mapa-br-242. Acesso em: 18 fev. 2019.

A construção de rodovias é uma atividade potencialmente impactante ao ambiente natural. Como correlato, com o propósito de mitigar, evitar e/ou compensar efeitos negativos, a Resolução nº 237/1997 do Conselho Nacional do Meio Ambiente - CONAMA (BRASIL, 1997) disciplina a obrigatoriedade do licenciamento ambiental de empreendimentos rodoviários e exige que, durante a fase de instalação da obra, seja desenvolvido o Programa de Gestão Ambiental com vários subprogramas, entre eles o de Educação Ambiental, foco da presente investigação.

O Programa de Educação Ambiental desenvolvido no município de Nova Ubiratã considerou como premissa básica as diretrizes da UNESCO (2005) sobre os objetivos da Educação Ambiental para o Desenvolvimento Sustentável (EAPDS), quais sejam: a integração dos princípios, valores e práticas do Desenvolvimento Sustentável em todos os aspectos da educação, tanto formal como não-formal, e mudanças de comportamento da população, possibilitando cenários futuros mais sustentáveis. De acordo com as orientações do referido órgão, três aspectos interligados devem ser considerados no conceito de Desenvolvimento Sustentável:

a) a sociedade organizada e o entendimento do papel das instituições sociais nos sistemas democráticos;

b) reconhecimento da fragilidade dos elementos do ambiente físico e o compromisso de abordar a questão ambiental nas políticas sociais e econômicas; 
c) a consciência em relação aos limites da utilização econômica dos elementos da natureza e o compromisso na redução do consumo e com a justiça social.

Subsidiados por esse pressuposto, entende-se a educação ambiental como eminentemente plural e composta por diferentes atores sociais, entre eles os gestores públicos municipais, que através das políticas, programas e projetos materializados na esfera local concentram o poder decisório e influenciam diretamente na qualidade socioambiental do espaço vivido. Nesse sentido, o presente artigo tem como principal objetivo analisar a forma como os gestores públicos municipais de Nova Ubiratã concebem as questões socioambientais e o papel desempenhado por eles na definição de políticas, programas e projetos sobre a temática. De forma concomitante, buscou-se investigar a estrutura de governança local, os mecanismos de controle social e estabelecer uma rede de atores com vistas ao desenvolvimento de ações de Educação Ambiental no âmbito formal e não-formal.

Diante de tais objetivos, o esforço analítico aqui empreendido transita por diferentes recortes, priorizando a releitura das abordagens dadas à Educação Ambiental, desde o quadro conceitual, passando pelas abordagens presentes nos instrumentos regulatórios de gestão ambiental, com ênfase nos princípios colocados pela UNESCO (2005) sobre os objetivos da Educação Ambiental para o Desenvolvimento Sustentável (EAPDS) e pelos Objetivos de Desenvolvimento do Milênio (UNESCO, 2000) propostos na perspectiva das três dimensões basilares do desenvolvimento sustentável: a econômica, a social e a ambiental. Tais pressupostos integram a primeira parte do artigo e subsidiam a elucidação dos resultados evidenciados.

$\mathrm{Na}$ segunda parte, registra-se a trajetória metodológica onde, apesar da proeminência das ações qualitativas, buscou-se correlacionar dados documentais com os dados resultantes da coleta de dados primários - observando-se as distinções necessárias. Já a terceira seção apresenta os resultados e busca situar a síntese analítica entre o arcabouço teórico e conceitual e a realidade vivida, enfatizando a forma como os gestores públicos municipais concebem as questões socioambientais, organizam a estrutura de governança local e o papel que desempenham na definição de políticas, programas e projetos. De forma concomitante, almejou-se identificar os mecanismos de controle social e estabelecer uma rede de atores locais com vistas ao desenvolvimento de ações de Educação Ambiental no âmbito formal e não-formal. 


\section{Revisitando os conceitos e o arcabouço legal}

Considerando a educação na perspectiva de Gadotti (2012, p. 3), “[...] é um fenômeno complexo, composto por um grande número de correntes, vertentes, tendências e concepções, enraizadas em culturas e filosofias diversas" e entendendo que as diversas realidades demandam ações e atividades alicerçadas em um viés filosófico, coadunamos com a lógica que "[...] toda educação é política, como nos ensinou Paulo Freire, ela não é neutra, pois, necessariamente, implica princípios e valores que configuram uma certa visão de mundo e de sociedade" (GADOTTI, 2012. p. 3). Assim, a perspectiva filosófica adotada é galgada no viés que todos os seres humanos são atores sociais e devem participar das decisões políticas que influenciam suas vidas. Para tanto, necessitam de formações para poderem desenvolver seus papéis sociais.

Nesse contexto, a educação e suas múltiplas facetas possibilitam que o sujeito possa tomar decisões alicerçadas em sua vivencia observando a complexidade das suas relações sociais e ambientais. Jacobi fortalece tal concepção entendendo que "a reflexão sobre as práticas sociais, em um contexto marcado pela degradação permanente do meio ambiente e do seu ecossistema, envolve uma necessária articulação com a produção de sentidos sobre a educação ambiental" (JACOBI, 2003. p. 190). Munidos do entendimento que a educação ambiental aponta o novo "paradigma ambiental tenderia a compreender, para além de um ecossistema natural, um espaço de relações socioambientais historicamente configurado" (CARVALHO, 2006. p. 241) e que seus sujeitos ecológicos sem forma e transformam a realidade. Nesse contexto, a educação ambiental é componente do viés do desenvolvimento sustentável.

O conceito de Educação Ambiental associado ao termo Desenvolvimento Sustentável resulta das diferentes perspectivas dos processos econômicos, conflitos e crises ecológicas globais. Como construção teórica, ambos buscam conciliar as preocupações com a preservação e a conservação dos elementos da natureza para as gerações futuras.

Sachs (1992) concebe o desenvolvimento sustentável como um processo que apresenta dimensões indissociáveis, destacando a sustentabilidade social, cultural, econômica e política como essenciais para manutenção do equilíbrio da natureza e da qualidade de vida das pessoas. Defende ainda a possibilidade de harmonização dos objetivos sociais e econômicos com a gestão 
racional dos recursos naturais, mediante a valorização das potencialidades da biodiversidade e da sociodiversidade de cada bioma. Para o autor, o processo de desenvolvimento sustentável deve ser assumido como um projeto de Estados e sociedades, cuja preocupação seja a sustentabilidade social e humana, no mesmo patamar que o desenvolvimento econômico.

Carvalho (2006) ressalta que a educação ambiental (EA), por sua vez, oportuniza aos atores sociais a problematização entre os diversos interesses e forças que se constituem em torno das questões ambientais. Como prática educativa reflexiva, abre possibilidades de compreensão e autocompreensão das questões ambientais em suas múltiplas dimensões. $\mathrm{Na}$ mesma intencionalidade, Quintas (BRASIL, 2013) estabelece vínculos entre a racionalidade capitalista e a educação, criticando o estereótipo da ordem social disseminada por processos educativos voltados apenas para mitigação dos impactos socioambientais e alicerçados na crença de que os recursos naturais são infinitos e a desigualdade social é um elemento necessário. Tal pensamento apenas alimenta o modelo insustentável existente e a Educação Ambiental só se torna eficiente ao proporcionar aos agentes envolvidos a compreensão dessa realidade insustentável com vistas à sua transformação.

Há convergências entre tais assertivas e alguns apontamentos de Jacobi (2003) ressaltam a necessidade de tempo para interiorização e compreensão da racionalidade do processo exploratório dos elementos da natureza; e quando o processo educativo ocorre de forma fragmentada, acaba resultando em pouca eficácia na condução de ações sustentáveis e na transformação dos estereótipos. Nesse sentido, a Educação Ambiental para o Desenvolvimento Sustentável pode ser entendida como um processo em que, de um lado entram em pauta os marcos institucionais e legais que normatizam os usos da natureza e, de outro, a multiplicidade das culturas, das relações sociais, as experiências tradicionais e vocações locais.

Sauvé (1997) tece considerações sobre o termo Educação Ambiental para o Desenvolvimento Sustentável (EAPDS), concluindo que essa abordagem se transforma no ponto central da análise crítica por adquirir expressão política cujo objetivo reside na integração dos princípios, valores e práticas do Desenvolvimento Sustentável em todos os aspectos da educação, tanto formal como não-formal, estimulando mudanças de comportamento e possibilitando cenários futuros mais sustentáveis. No que tange às diferentes concepções sobre a Educação, Ambiente e Desenvolvimento Sustentável, a autora compactua com o pensamento de que não há 
a necessidade de definições padronizadas, argumentando que a diversidade é fonte de reflexão crítica e auxilia os educadores na elaboração das suas concepções pessoais e na materialização das suas práticas educativas.

A contundência do enfoque da Educação Ambiental para o Desenvolvimento Sustentável na perspectiva crítica é ressaltada por Jacobi (2003), que reitera que a educação para a cidadania é o principal desafio do século XXI. Tal processo, na concepção do autor, é um ato político voltado para a transformação social com enfoque na perspectiva holística. Assim, envolve uma multiplicidade de grupos sociais e se materializa na transformação do sujeito em ator corresponsável pela defesa da qualidade de vida e do ambiente.

Depreende-se, então, que a noção de sujeito está atrelada ao sujeito individual e ao sujeito coletivo, sendo que este último corresponde à sociedade civil organizada e às instituições governamentais que assumem a corresponsabilidade nos processos de gestão e educação ambiental em diferentes escalas geográficas. Este cenário, que possui dimensão planetária, requer um olhar sobre os pressupostos de agências internacionais como a Organização das Nações Unidas (ONU) que estabeleceu em 2000 os Objetivos de Desenvolvimento do Milênio (ODM) e as respectivas metas que abrangem os problemas sociais derivados da pobreza e da miséria, estabelecendo prazos e estimulando os países a seguirem uma agenda internacional. Entre os objetivos, destaca-se a garantia pela qualidade de vida, respeito ao meio ambiente e o estabelecimento de parcerias para o desenvolvimento.

Ao analisar o papel dos agentes envolvidos em prol do alcance dos Objetivos de Desenvolvimento do Milênio (ODM), Rezende (2008) afirma que os Estados nacionais têm função essencial e prioritária para reduzir a pobreza absoluta, as exclusões e a defesa do meio ambiente. No Brasil, o Estado é representado por instituições, a exemplo do Instituto Brasileiro de Recursos Naturais Renováveis (IBAMA), que, através da Instrução Normativa No 02 de 27/03/2012 (IBAMA, 2012), reitera a importância da educação não formal nas ações de mitigação e compensação ambiental, estabelecendo papéis diferenciados aos entes institucionais que compõem os sistemas nacionais de meio ambiente e educação. O referido documento e as respectivas diretrizes colocadas pelo Anexo - Bases Técnicas para Elaboração dos Programas de Educação Ambiental no Licenciamento Ambiental Federal ressaltam a necessidade de compreensão "da interdependência econômica, social, política e ecológica [...] proporcionando a 
todas as pessoas a possibilidade de adquirir conhecimentos, o sentido dos valores, atitudes, interesse ativo, aptidões e habilidades necessárias à proteção e melhoria do meio ambiente" (IBAMA, 2012, p. 130).

Compreendemos que os processos educativos extrapolam a seara formal e não-formal da educação e possibilitam que os sujeitos sociais sejam atores nos processos de transformação social, oportunizando novos diálogos e formando novos cenários de relação sociedade-natureza. (BRASIL, 2013. p. 30).

O papel atribuído às comunidades se torna relevante no momento em que, através de conselhos e outras formas de participação como sociedade civil organizada, passam a exercer o controle social. Sobre essa estratégia já se debruçara Coutinho (2006), ao afirmar que a expressão controle social é designada como controle da sociedade civil sobre o Estado e sua efetivação e requer a articulação política que represente os interesses das classes.

Os mecanismos de controle social se efetivam nas várias instâncias da gestão pública, entre elas na esfera municipal. Gomes (2003) conceitua conselho municipal como um colegiado institucionalizado - composto de um pequeno número de representantes do governo e da sociedade civil, estes designados democraticamente - que é responsável pela gestão de uma determinada política pública. Todavia, em sentido amplo, o controle social pode ser entendido como o conjunto de ações, individuais ou coletivas, que a sociedade realiza de forma cotidiana, pressionando os governos no atendimento de suas demandas, acompanhando e controlando as políticas públicas, desde sua formulação até a sua implementação.

\section{Trajetória metodológica: provocando o protagonismo}

Os pressupostos metodológicos adotados na presente pesquisa estão subsidiados pelo pressuposto que as pessoas agem em função de suas crenças, percepções, sentimentos e valores e que, para todo comportamento humano há um sentido, uma interpretação (MINAYO, 1998). Assim, optou-se pela abordagem qualitativa, pela observação direta dos participantes e suas manifestações verbais durante o diagnóstico socioambiental participativo.

A referida ação é recomendada como premissa básica para os Programas de Educação Ambiental, especialmente para o conhecimento das "[...] especificidades locais e os impactos 
gerados pela atividade em licenciamento sobre os diferentes grupos sociais presentes em suas áreas de influência" (IBAMA, 2012, p. 130). Assim, os gestores públicos municipais integraram o primeiro grupo participante da oficina de diagnóstico socioambiental participativo, uma vez que o papel dos governos na construção de políticas integradas é um dos temas considerados de fundamental importância para a consecução dos Objetivos de Desenvolvimento do Milênio (ODM).

Durante a oficina, a técnica utilizada foi a de Planejamento de Projetos Orientados por Objetivos (ZOOP) - Fase de diagnóstico e a técnica da moderação e uso de perguntas, adaptada ao contexto em investigação (BOLAY, 1993). Para cada pergunta foram feitas fichas e os participantes respondiam individualmente e a equipe compilava em slides que, em momento posterior, foram apresentados e discutidos de forma coletiva, cabendo à equipe o registro dos discursos dos participantes, sua argumentação e defesa da postura adotada. O Quadro 1 apresenta o roteiro de questões respondidas pelos participantes.

Quadro 1- Roteiro das questões discutidas na oficina Diagnóstico Socioambiental Participativo - Nova Ubiratã (MT)

\begin{tabular}{|l|l|}
\hline $\mathbf{N}$ & \multicolumn{1}{|c}{ Pergunta } \\
\hline $\mathbf{1}$ & Escreva um problema relevante da realidade socioambiental do município onde você mora. \\
\hline $\mathbf{2}$ & Escreva duas consequências do problema. \\
\hline $\mathbf{3}$ & Escreva como você acha que esse problema pode ser resolvido. \\
\hline $\mathbf{4}$ & Quem é o responsável pelas ações que resolveriam o problema? (Pode ser mais de 1) \\
\hline
\end{tabular}

Fonte: Elaborado pelas autoras.

De forma complementar, realizou-se a coleta de dados secundários disponíveis nos sites das prefeituras, levantamento da produção científica sobre a região e a população da área de influência da BR-242/MT e pesquisa documental visando levantar formas de intervenção do poder público, legislações e normas específicas. Os dados coletados nas diferentes fontes foram analisados inicialmente de forma isolada e depois articulados entre si e com os elementos do diagnóstico socioambiental participativo, resultando em importantes subsídios que nortearam as ações efetivas do Programa de Educação Ambiental. 


\section{Pensando o contexto vivido e apreendendo a realidade socioambiental}

Os significados dos elementos do meio ambiente não são iguais para todos os atores sociais. Cada um enxerga o mundo através de seus valores, experiências e filtros seletivos da memória, acrescidos do conhecimento adquirido na ciência formal. Nas palavras de Leff (2003, p. 55), “[...] os problemas ambientais são, fundamentalmente, problemas do conhecimento”. Isto tem fortes implicações para toda a política ambiental - que deve passar por uma política do conhecimento - e para a educação. A Tabela 1 apresenta os resultados do grupo de gestores públicos que impulsionam as políticas locais em Nova Ubiratã.

Tabela 1 - Principais problemas socioambientais, consequências, alternativas e agentes responsáveis pela solução e/ou mitigação - Município de Nova Ubiratã (MT)

\begin{tabular}{c|c|c|c|c}
\hline $\begin{array}{c}\text { Principais Problemas } \\
\text { Ambientais } \\
\text { Identificados }\end{array}$ & $(\boldsymbol{\%})$ & $\begin{array}{c}\text { Consequências } \\
\text { socioambientais }\end{array}$ & $\begin{array}{c}\text { Alternativas de } \\
\text { solução }\end{array}$ & $\begin{array}{c}\text { Agente (s) responsável } \\
\text { (is) para solucionar }\end{array}$ \\
\hline $\begin{array}{l}\text { Ausência de políticas } \\
\text { públicas para a coleta, } \\
\text { reciclagem e depósito do } \\
\text { Lixo. }\end{array}$ & 35 & Problemas de saúde. & $\begin{array}{l}\text { Educação; Ações } \\
\text { no sentido de } \\
\text { recolher, reciclar } \\
\text { e depositar. }\end{array}$ & $\begin{array}{l}\text { Poder Público } \\
\text { Municipal; Escolas. }\end{array}$ \\
\hline $\begin{array}{l}\text { Aumento dos processos } \\
\text { erosivos. }\end{array}$ & 33 & $\begin{array}{l}\text { Assoreamento dos } \\
\text { rios. }\end{array}$ & $\begin{array}{l}\text { Sensibilizar os } \\
\text { produtores rurais; } \\
\text { Capacitar os }\end{array}$ & $\begin{array}{l}\text { Poder Público Municipal } \\
\text { e Estadual. }\end{array}$ \\
\hline $\begin{array}{c}\text { técnicos. } \\
\text { reservas ambientais. }\end{array}$ & 25 & $\begin{array}{c}\text { Destruição da } \\
\text { natureza. }\end{array}$ & $\begin{array}{c}\text { Aumentar a } \\
\text { fiscalização. }\end{array}$ & $\begin{array}{c}\text { Municipal, Estadual, } \\
\text { Federal. }\end{array}$ \\
\hline
\end{tabular}

Nota: Organizado pelas autoras.

Fonte: OFICINA Diagnóstico Socioambiental Participativo - BR-242/MT. Nov. 2015. (Oficina organizada pelas autoras).

A preocupação com as políticas públicas para destinação correta do lixo foi o principal problema apontado pelos participantes. Bertoline e Possamai (2005) consideram lixo todos os materiais que não têm condições de serem reaproveitados e reciclados, ou cujos produtos resultantes desses processos podem gerar componentes inseguros do ponto de vista sanitário. $\mathrm{Na}$ 
ROSSETTO, Onelia Carmem; NORA, Giseli Dalla. Ações ambientais no processo de gestão de empreendimentos rodoviários na Amazônia Mato-Grossense.

perspectiva dos atores locais, o efeito do lixo para a saúde humana é colocado como a principal consequência negativa, contribuindo para o aumento da ocorrência de diversas doenças, causando óbitos e gerando despesas com hospitalizações e medicamentos, além de criar condições favoráveis à proliferação de vetores ou de insetos indesejáveis. Além disso, colabora para o aumento da poluição nos diferentes elementos da natureza.

Waldman (2013) ressalta a necessidade de bons operadores e equipes de trabalho capacitadas para atuarem na gestão dos resíduos sólidos e a necessidade de reflexões sobre o modelo produtivo e de consumo principalmente na gestão dos resíduos domiciliares. Desatentos a tais recomendações, a questão do tratamento adequado para o lixo urbano é vista com uma necessidade no discurso dos gestores locais de Nova Ubiratã. Entretanto, no âmbito das políticas públicas expressas através de projetos e programas municipais, verifica-se baixo nível de prioridade e as alternativas identificadas para minimizar/solucionar o problema residem em esforços para recolher e depositar o lixo em locais distantes, pois os dados secundários revelam que o lixo seco produzido em Nova Ubiratã é transportado para o Distrito de Primavera do Norte, no município de Sorriso e o lixo úmido é destinado para uma área próxima à zona urbana.

Através do projeto denominado Cidade Limpa, o poder público municipal busca realizar a coleta seletiva e a compostagem orgânica, cujo material é utilizado em projetos de hortas comunitárias, parques e praças. Durante a coleta de dados em campo obteve-se o acesso a um material educativo (folder com orientações e calendário de coleta de lixo) que foi escrito/divulgado pelas Secretarias Municipais, onde o papel da prefeitura é a coleta de lixo domiciliar, planejamento e execução de cronogramas de coletas de entulhos, limpeza de lotes baldios, campanhas de sensibilização e medidas punitivas.

Embora a reciclagem tenha assumido certa relevância no discurso dos participantes, não foi registrada nenhuma preocupação com a educação para o consumo consciente e a consequente diminuição da produção de lixo, nem tampouco foi mencionada a preocupação com a deposição e reciclagem dos resíduos produzidos na área rural, haja vista que o município faz uso de elevada quantidade de agroquímicos nas lavouras de soja. Segundo os documentos analisados, entre os Programas da Secretaria Municipal de Meio Ambiente e Agricultura identificou-se um voltado para manutenção e adequação do aterro de resíduos sólidos do município, entretanto, no momento da pesquisa, encontrava-se inativo. 
O aumento dos processos erosivos, preocupação de $33 \%$ dos participantes, não foi relacionado à inserção do município no Bioma Amazônia, suas características naturais e a necessidade de conservação e/ou preservação. Contudo, durante o debate, registrou-se a preocupação de rever o modelo de exploração econômica do município, onde as atividades são voltadas para a indústria madeireira e a monocultura de soja. Mingoti et al. (2017) afirmam que 312.830 hectares são utilizados para o plantio de soja no município de Nova Ubiratã, $6^{\circ}$ maior produtor de grãos do Estado de Mato Grosso e integrante do ranking dos 20 municípios com maior produção de soja do país.

A erosão dos solos é decorrente da remoção da vegetação e da movimentação da terra, devido à interação de vários fatores, tais como a alta precipitação pluviométrica, fragilidade do solo, manejo e práticas conservacionistas inadequadas, que resultam em impactos ambientais negativos acarretando em compactação, erosão e perda do solo em grandes proporções. Entre os objetivos da Secretaria Municipal de Meio Ambiente e Agricultura constam a recuperação de áreas degradadas por erosão e um projeto voltado para gestão pública de riscos urbanos, que resultou da parceria estabelecida entre a Secretaria Municipal de Meio Ambiente e outras instituições/secretarias.

Jesus e Carvalho (2017) ressaltam que, para efetividade dos programas de controle dos processos erosivos, faz-se necessário intensificar as ações voltadas para a educação ambiental formal e não-formal, além da atuação preventiva e, em certos casos, mitigadora por parte do poder público, cuja visão deve ser ampliada. Ou seja, a erosão não é apenas um problema administrativo, mas também de segurança pública, desigualdade social, educação e saúde pública, em síntese, um problema socioeconômico.

Desse modo, ao analisar os objetivos propostos pelos programas elaborados e executados pelos gestores públicos de Nova Ubiratã, constata-se a preocupação com a educação ambiental, em especial em relação à geração de resíduos sólidos, aos processos erosivos e ao desmatamento, embora, as ações práticas de intervenção na realidade ainda careçam de implantação e implementação, tanto no sentido quantitativo como no qualitativo.

O desmatamento das reservas ambientais aparece em terceiro lugar entre as preocupações dos participantes da oficina (25\%). Eles fazem referência às áreas de reserva legal das propriedades e também às ações praticadas na Estação Ecológica do Rio Ronuro e parte da Área 
Indígena do Parque Nacional do Xingu, ambas localizadas no perímetro do município de Nova Ubiratã. É interessante registrar que cerca de $80 \%$ dos participantes da oficina nunca estiveram nesses locais e a observação direta da realidade local evidenciou a ausência de indígenas, ou mesmo de artesanato desses povos no perímetro urbano.

No que se refere aos principais responsáveis pela mitigação e/ou solução dos problemas socioambientais, observou-se, de forma generalizada, que cerca de $98 \%$ dos participantes da oficina atribuíram a responsabilidade ao poder público em duas esferas: municipal e federal; e nenhuma resposta registrou a importância da população como corresponsável pelo meio ambiente, nas ações individuais e coletivas, inclusive exercendo sua cidadania fiscalizando, denunciando e cobrando melhores investimentos e condições para o município.

Outrossim, é relevante ressaltar que os participantes da oficina representavam o poder público municipal, mas não se autoidentificavam como responsáveis pelas ações, sempre atribuindo ao ente governamental da escala estadual ou federal a culpabilidade da ineficiência ou ausência das políticas e projetos. A lógica evidenciada é que, na escala municipal, a atuação dos gestores públicos ocorre apenas no âmbito da execução das políticas e não na esfera da elaboração e gestão.

Num sentido empírico, percebemos que as perspectivas dos entrevistados são, de maneira geral, convergentes, apresentando similaridades na concepção do conceito de Educação Ambiental, sempre voltado à educação formal, às crianças e aos jovens, passando a ideia de que os adultos presentes na oficina não necessitavam de tais subsídios.

\section{Estrutura de governança municipal e mecanismos de controle social}

Para criação e implantação de políticas públicas municipais condizentes com a realidade local, fazem-se necessárias, entre outros fatores, uma estrutura de governança condizente e ações regulatórias como o arcabouço legal e normativo. O termo governança é concebido por Frey (2007, p. 138) como "[...] novas tendências de uma gestão compartilhada e interinstitucional que envolve o setor público, o setor produtivo e o crescente terceiro setor". De forma geral, a estrutura de governança reflete a capacidade que os governos têm de criar condições e de responder às demandas da sociedade. 
O município de Nova Ubiratã possui as principais leis que regulam as condições municipais para o enfrentamento dos problemas socioambientais conforme apresentado no Quadro 2.

Quadro 2 - Estrutura de Governança municipal: Arcabouço Legal e Normativo do Município de Nova Ubiratã (MT)

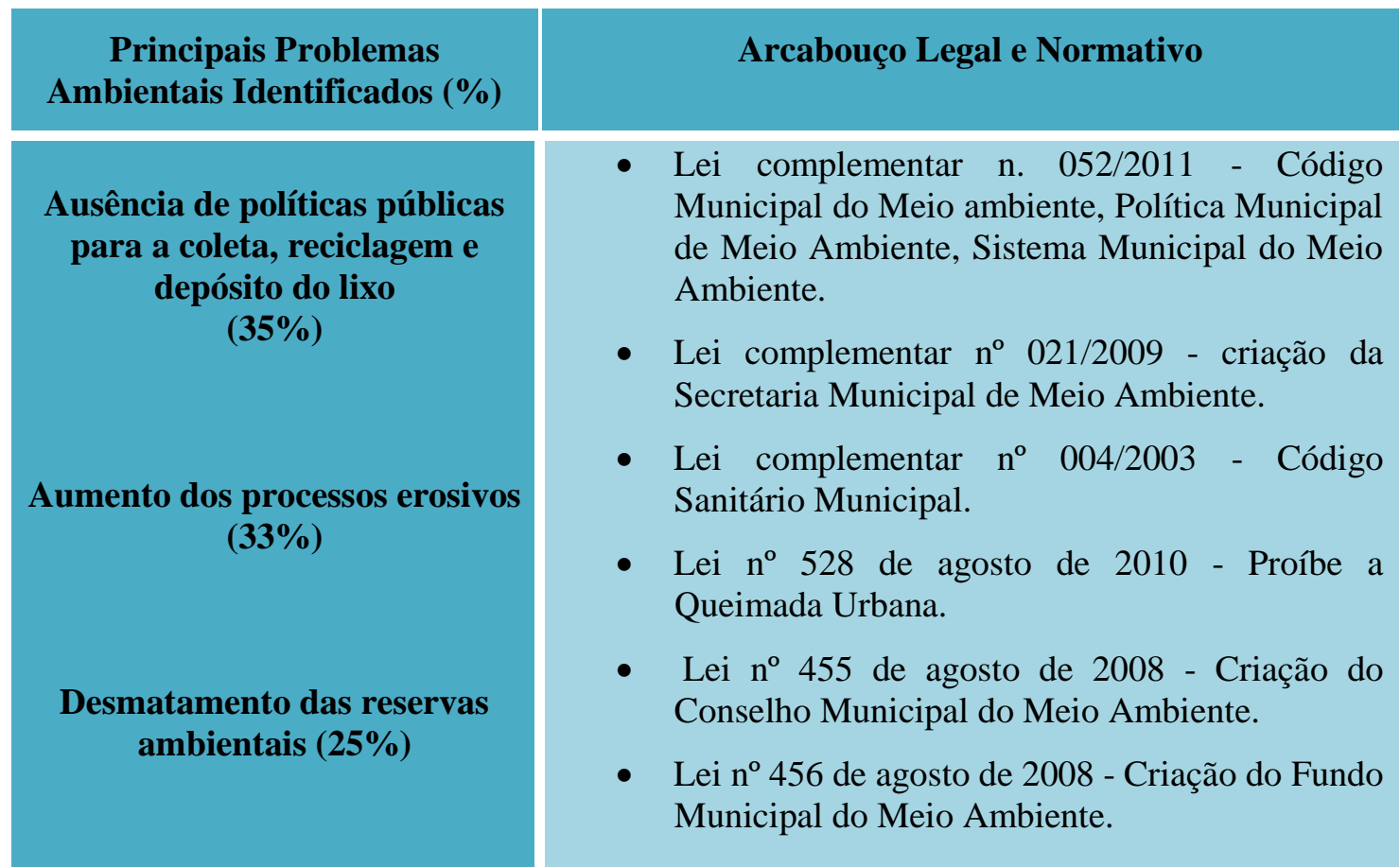

Nota: Organizado pelas autoras.

Fonte: PESQUISA Documental - BR-242/MT. Nov. 2015. (Oficina organizada pelas autoras).

A análise do quadro denota a materialidade dos textos legais. Porém, ao investigar a estrutura de governança que propicia sua aplicação, registra-se que a Secretaria de Meio Ambiente e Agricultura é ocupada por um único gestor, com funcionários que respondem por ambas as pastas. Como o Município tem sua base econômica centrada no agronegócio da soja, é paradoxal constatar que a preservação e a conservação ambiental estão sob os auspícios de uma só equipe. Segundo informações coletadas em campo, tal número de técnicos é insuficiente para gerir duas pastas de extrema relevância na administração municipal.

A Secretaria Municipal de Educação não apresentou nenhum programa direcionado especificamente para Educação Ambiental, e desmistificar o estereótipo que a educação 
ambiental diz respeito apenas à educação formal não se mostrou tarefa fácil, nem entre os profissionais da educação e nem entre os gestores públicos, haja vista que as ideias consolidadas necessitam do tempo lento para serem interiorizadas.

Os mecanismos de controle social no município de Nova Ubiratã são os conselhos, entretanto, os dados coletados em campo permitem afirmar que a participação popular nos processos de formulação de políticas públicas e de tomada de decisões é parcial porque os conselhos criados não representam instâncias deliberativas e sim consultivas. No Sistema Municipal de Meio Ambiente registrou-se o Conselho Municipal de Meio Ambiente (CONSEMMA), criado em 2008, de caráter consultivo e orientativo, com a atribuição de organizar, coordenar e integrar as ações dos órgãos de administração pública, direta e indiretamente, e assegurar a participação da comunidade. O referido Conselho tem apenas uma câmara técnica municipal responsável pela análise prévia das matérias, seus membros são representantes de 05 entidades e/ou instituições governamentais e não-governamentais. Apesar de contar com cinco anos de criação, o CONSEMMA de Nova Ubiratã ainda não possui regimento interno, segundo as fontes orais pesquisadas; o conselho foi criado, porém, nunca funcionou efetivamente.

A fragilidade dos conselhos analisados evidencia que seu papel transformador e emancipador da população local está sendo burlado, ou seja, seu fortalecimento nos âmbitos social, cultural e político na busca de uma sociedade mais justa transforma-se em um simulacro para políticas de interesse individual em detrimento dos interesses coletivos. Como asseguram Santos e Saito,

O conceito de participação é apropriado e deturpado pelo setor dominante da sociedade como forma de obter uma pretensa legitimidade social às suas decisões, sendo esta prática normalmente evocada nos momentos de crise, como forma de contornar processos de mobilização e crítica [...] (2006, p. 55).

Constatou-se que o controle social apenas através dos conselhos como instâncias deliberativas e não decisórias desconsideram medidas como denúncias, ações, protestos e excluem a participação democrática.

Com base no Diagnóstico Socioambiental Participativo, que representou as preocupações socioambientais dos atores locais e suas perspectivas de mitigação/solução e no entendimento do papel das instituições sociais na escala local, buscou-se delinear e realizar ações educativas no 
âmbito da educação formal e não-formal, cujas intencionalidades estimulassem mudanças de comportamento dos atores locais, principalmente em relação ao entendimento que a Educação Ambiental para o Desenvolvimento Sustentável (EAPDS) ultrapassa a proteção dos ambientes naturais e que estes podem ser manejados de forma sustentável, considerando os direitos das populações, a igualdade e a solidariedade com as gerações futuras.

\section{Considerações finais}

Considerando que os objetivos da pesquisa se centraram na análise de como os gestores públicos e a sociedade cível concebem os problemas socioambientais, e como os mesmos têm atuado frente às questões ambientais, identificamos que o Bioma Amazônia enfrenta sérias ameaças à sua sobrevivência devido a interesses globais e nacionais, principalmente a partir da voracidade dos fluxos econômicos que exigem a instalação de infraestrutura para atender o agronegócio, principalmente de grãos. Os atores locais envolvidos nesse processo se tornam hegemônicos no âmbito das concepções e ações, uma vez que, quase por unanimidade, têm a ideia do progresso relacionada à instalação de grandes obras que possibilitem a geração de energia e o transporte dos produtos.

Ademais, entre os atores sociais participantes da pesquisa, o ambiente amazônico onde residem é percebido em face dos problemas ambientais, que interferem diretamente na vida das pessoas, afetando seu bem-estar - e não porque podem trazer danos ao Bioma e posteriormente atingi-los, constata-se que as questões ambientais são compreendidas, especialmente, pelo seu viés utilitário aos seres humanos.

Os impactos socioambientais resultantes do acréscimo de modais rodoviários podem ser mitigados pelas ações da Educação Ambiental para o Desenvolvimento Sustentável (EAPD). Contudo, no bojo desse processo se faz necessário, como ponto de partida, o conhecimento da realidade local e, como ponto de chegada, a construção do conhecimento científico aliado ao conhecimento empírico. Assim, os atores sociais aprimoram sua sensibilidade no entendimento das questões ambientais e realizam ações para mitigar ou resolver os impactos.

Ao observarmos a governança em relação às questões ambientais, percebe-se que a estrutura existe com a secretaria de meio ambiente, com os conselhos municipais e com 
ROSSETTO, Onelia Carmem; NORA, Giseli Dalla. Ações ambientais no processo de gestão de empreendimentos rodoviários na Amazônia Mato-Grossense.

participação social. Entretanto, a realidade de monitoramento ainda exige maior formação aos atores sociais envolvidos, observando que os mesmos promovem a articulação entre as ações e os mecanismos de controle social.

A compreensão do ambiente como um conjunto de interações entre diversos elementos e os efeitos negativos generalizados resultantes do desequilíbrio de um aspecto do sistema é premissa essencial para os gestores públicos entenderem a totalidade socioambiental e sua corresponsabilidade pelas ações, uma vez que detêm o poder decisório. Diante disso, as pesquisas e as ações no âmbito da Educação Ambiental permitem compreender os valores dos atores locais, bem como, tais concepções se traduzem em ações. Tais resultados revelam, portanto, importantes nuances a serem observadas no escopo das iniciativas públicas sobre o ambiente - em especial quanto à educação ambiental e aos demais processos no âmbito da educação formal e não-formal.

\section{Referências}

BERTOLINI, Geysler Rogis Flor; POSSAMAI, Osmar. Proposta de instrumento de mensuração do grau de consciência ambiental, do consumo ecológico e dos critérios de compra dos consumidores. Revista de Ciência e Tecnologia, São Paulo, v. 13, n. 25/26, p. 17-25, 2005.

BOLAY, Fred. Walle. Guia para aplicação: planejamento de projeto orientado por objetivos- método Zopp. Recife: GTZ, 1993.

BRASIL. Conselho Nacional do Meio Ambiente - CONAMA. Resolução no 237, de 19 de dezembro de 1997. Dispõe sobre a revisão e complementação dos procedimentos e critérios utilizados para o licenciamento ambiental e altera a Resolução no 1/86 (revoga os art. $3^{\circ}$ e $7^{\circ}$ ). 1997. Disponível em: http://www.mma.gov.br/port/conama/legislacao/CONAMA_RES_CONS_1997_237.pdf. Acesso em: 12 jun. 2017.

BRASIL. Ministério do Meio Ambiente. Educação ambiental na gestão pública: uma entrevista com José Quintas. Educação Ambiental e Agricultura Familiar. COLECIONA: Fichário d@ Educador

Ambiental. 13. ed. Brasília: MMA, 2013. Disponível em:

https://www.mma.gov.br/publicacoes/educacao-ambiental/category/99-periodico-coleciona.html. Acesso em: 10 out. 2017.

CARVALHO, Isabel Cristina de Moura. Educação ambiental: a formação do sujeito ecológico. São Paulo: Cortez, 2006.

COUTINHO, Carlos Nelson. Intervenções: o marxismo na batalha das ideias. São Paulo: Cortez, 2006.

FREY, Klaus. Governança urbana e participação pública. RAC-Eletrônica, Rio de Janeiro, v. 1, n. 1, p. 136-150, jan./abr. 2007. Disponível em: https://www.researchgate.net/profile/Klaus_Frey/publication/ 26503623_Governanca_Urbana_e_Participacao_Publica/links/05b2937a584eee4807d3745f.pdf. Acesso em: 11 nov. 2017. 
ROSSETTO, Onelia Carmem; NORA, Giseli Dalla. Ações ambientais no processo de gestão de empreendimentos rodoviários na Amazônia Mato-Grossense.

GADOTTI, Moacir. Educação popular, educação social, educação comunitária. In: CONGRESSO INTERNACIONAL DE PEDAGOGIA SOCIAL. Porto Alegre, 2012. Disponível em http://www.proceedings.scielo.br/pdf/cips/n4v2/13.pdf. Acesso em: 11 abr. de 2018.

GOMES, Eduardo Granha Magalhães. Conselhos gestores de políticas públicas: democracia, controle social e instituições. 2003. 225f. Dissertação (Mestrado em Administração Pública e Governo) - Escola de Administração de Empresas de São Paulo, Fundação Getúlio Vargas, São Paulo, 2003.

IBAMA. INSTITUTO BRASILEIRO DE RECURSOS NATURAIS RENOVÁVEIS. Instrução Normativa $\mathrm{N}^{\circ}$ 02, de 27 de março de 2012. Diário Oficial da União, Brasília, 29 de março de 2012. Seção 1. Disponível em: http://ibama.gov.br/sophia/cnia/legislacao/IBAMA/IN0013-181212.PDF. Acesso em: 12 jul. 2017.

JACOBI, Pedro. Educação ambiental, cidadania e sustentabilidade. Cadernos de Pesquisa, São Paulo, $\mathrm{n}$. 118, p. 189-205, mar. 2003. Disponível em: http://www.scielo.br/pdf/cp/n118/16834.pdf. Acesso em: 19 nov. 2013.

JESUS, Andrelisa Santos de; CARVALHO, José Camapum de. Processos erosivos em área urbana e as implicações na qualidade de vida. Boletim Goiano de Geografia, Goiânia, v. 37, n. 1, p. 1-17, abr. 2017. Disponível em: https://revistas.ufg.br/bgg/article/view/46239. Acesso em: 18 fev. 2019.

LEMOS, André Luiz Ferreira; SILVA, José de Arimatéia. Desmatamento na Amazônia legal: evolução, causas, monitoramento e possibilidades de mitigação através do fundo Amazônia. Floresta e Ambiente, Rio de Janeiro, v. 18, n. 1, p. 98-108, 2011.

LEFF, Enrique. A complexidade ambiental. São Paulo: Cortez, 2003.

MATO GROSSO. Lei Estadual no 6691 de 30 de novembro de 1995, que dispões sobre a criação do município de Nova Ubiratã. Mato Grosso, 1995. Disponível em https://www.al.mt.gov.br/storage/webdisco/leis/lei-6691-1995.pdf. Acesso em: 18 fev. 2019.

MINAYO, Maria Cecília de Souza. Introdução à metodologia de pesquisa social. São Paulo: Hucitec, ABRASCO, 1998.

MINGOTI, Rafael. Et al. Mapeamento de Cenários Agrícolas para Avaliação de Risco Ambiental de Agrotóxicos em Água Superficial. In: SIMPÓSIO BRASILEIRO DE SENSORIAMENTO REMOTO (SBSR), 18., 2017, Santos. Anais [...]. Santos, SP: 2017. ISBN: 978-85-17-00088-1. Disponível em: https://www.alice.cnptia.embrapa.br/alice/bitstream/doc/1076501/1/2017 MingotiSBSRANAIS.pdf. Acesso em: 25 mar. 2018.

REZENDE, María José de. Os objetivos de desenvolvimento do milênio da ONU: alguns desafios políticos da co-responsabilização dos diversos segmentos sociais no combate à pobreza absoluta e à exclusão. Investigación \& Desarrollo, Barranquilla, v. 16, n. 2, p.184-213, 2008. Disponível em: http://www.scielo.org.co/scielo.php?script=sci_abstract\&pid=S0121-32612008000200003. Acesso em: 18 fev. 2018.

SACHS, Ignacy. Caminhos para o desenvolvimento sustentável. Rio de Janeiro: Garamond, 1992.

SANTOS, Irenilda Ângela dos; SAITO, Carlos Hiroo. A mitificação da participação social na política nacional de recursos hídricos: gênese, motivação e inclusão social. Geosul, Florianópolis, v. 21, n. 42, p. 7-27, jul./dez. 2006.

SAUVÉ, Lucie. Educação ambiental e desenvolvimento sustentável: uma análise complexa. Revista de Educação Pública, Cuiabá, v. 10, n. 10, p. 72-102, 1997. Disponível em: http://www.ufmt.br/revista/arquivo/rev10/educacao_ambiental_e_desenvolvim.html. Acesso em: 2 jun. 2016. 
ROSSETTO, Onelia Carmem; NORA, Giseli Dalla. Ações ambientais no processo de gestão de empreendimentos rodoviários na Amazônia Mato-Grossense.

UNESCO. Década das nações unidas para educação e desenvolvimento sustentável: 2005-2014 . Documento final: plano internacional de implementação. Brasília: UNESCO, 2005. Disponível em: https://unesdoc.unesco.org/ark:/48223/pf0000139937_por. Acesso em: 20 nov. 2016.

UNESCO. Objetivos de desenvolvimento do milênio. Brasília: UNESCO, 2000. Disponível em: http://www.fiocruz.br/omsambiental/media/ODMBrasil.pdf. Acesso em: 20 nov. 2016.

WALDMAN, Maurício. Lixo domiciliar brasileiro: modelos de gestão e impactos ambientais. Boletim Goiano de Geografia, Goiânia, v. 33, n. 2, p. 169-184, maio/ago. 2013. Disponível em: https://revistas.ufg.br/bgg/article/view/25553/15592. Acesso em: 18 fev. 2019. 